\title{
DERECHO COMPARADO
}

\section{Las Cortes de Equidad \\ en el sistema de la "Common Law"}

\section{Por el Dr. ALDO ICARDI}

En el sistema de la "Common Law", las Cortes de Equidad (Courts of Equity) constituían una verdadera entidad jurídica, independiente en su jưrisdicción, aun muchas veces concurrente con la jurisdicción de las Cortes de Ley (Courts of Law), y completamente autónoma en su jurisprudericia y administración.

Para comprender mejor su identidad singular, que dá, en efecto, al sistema de la "Common Law" el carácter heterodoxo de tener dos cortes de primera instancia con jurisdicción sobre el mismo sujeto y los mismos hechos (aunque diferenciados por la naturaleza de la acción y su solución) es necesario conocer las fuentes históricas y el carácter del sistema de la "Common Law" en sus origenes y en su desenvolvimiento.

La ocupación de las Islas Británicas por los Romanos hasta el siglo $5^{\circ}$ de nuestra era no ha dejado ninguna huella importante, aunque existen hasta la fecha ciertos restos arquitectónicos. No aparece pues ninguna evidencia de que alguna influencia del sistema jurídico Romano haya sobrevivido en las Islas Británicas después de la partida de los Romanos.

La invasión de Inglaterra por los Daneses, conocidos comúnmente con al nombre de Sajones, durante la Edad Media, no ha contribuído de manera alguna al desarrollo del patrimonio legal de Inglaterra. Además, es curioso notar que no solamente los Sajones no impusieron su civilización a Inglaterra, sino que fueron fácilmente y rápidamente absorbidos por las tribus que habitaban las Islas, y adquirieron la denominación universalmente conocida desde entonces de Anglo-Sajones. Se duda mucho de que los Sajones implantaron algún sistema jurídico y si lo tuvieron, éste debe haberse perdido al integrarse al pueblo inglés, porque no hay pruebas de la adopción de un sistema de derecho como consecuencia de esa invasión.

Los pueblos que vivían en Inglaterra hasta la invasión de los Normandos que culminó con la batalla de Hastings (1066), cuando Guillermo ei Normando derrotó a las fuerzas inglesas unidas bajo la dirẹcción de $\mathrm{Ha}$ told, fueron organizados en unidades sociales aisladas que no eran mucho más que tribus, y por consiguiente, su cultura limitada y su sencillo modo de vivir no podrian dar lugar a normas legales superiores a las que exigía su propia naturaleza. 
La invasión Normanda fué destinada a seguir la misma suérte que la Invasión Danesa. Aunque constituían un pueblo fuerte y característico, los Normandos también fueron absorbidos por los Ingleses, y por eso, se puede decir que, al final, los conquistadores se transformaron en conquistados. Pero, esta vez, los invasores llevaron a las Islas su idioma y organización política, los que tuvieron una influencia considerable en la historia de Inglaterra y en sus instituciones. No se sabe con exactitud si los Normandos usaban un sistema de derecho basado en el Código de Justiniano, pero es cierto que ellos no llevaron a Inglaterra ni el Código de Justiniano, ni otro sistema organizado de derecho. Por otra parte, teniendo en cuenta sus ideas avanzadas sobre las instituciones políticas, han estimulado sin duda alguna las instituciones nativas existentes y su organización social más compleja probablemente ha contribuído mucho al desenvolvimiento de nuevos métodos legales.

Después de sus triunfos sobre los Anglo-Sajones, los Normandos, encabézados por Guillermo, comenzaron a recoger la cosecha: Inglaterra fué dividida en porciones entregadas a nobles Normandos bajo una organización feudal, debiendo todos ellos lealtad al Rey, supremo señor.

Tampoco entonces fué necesario un sistema de derecho complejo, porque, aunque lus señores feudales fueron vasallos del Rey, fuera de este homenaje, los señores fueron gobernadores absolutos de sus dominios.

Sin embargo, con el impulso de la sociedad renovada, el crecimiento de ciudades libres, el comercio que se desarrolla entre ellas, y la decadencia gradual del feudalismo, las instituciones jurídicas comenzaron a formarse y las Cortes Reales que periódicamente se desplazabạn a través del reino administraban una justica rígida y limitada por las formas de acción permisibles arte este tribunal. Por costumbre y usos estas cortes permitían solamente las acciones de traspaso, trover, replevin y essumpsit. Estas acciones tenían solamente por fin la reparación de daños en dinero, y la restitución de

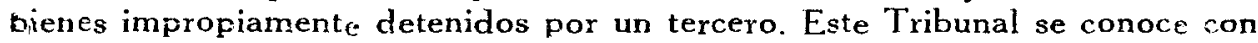
el nombre de Corte de Ley (Court of Law).

En su posición de Señor Supremo de todo Inglaterra, el Rey fué responsable de muchos abusos; esto, añadido a las dificultades evidentes de un sistema judicial muy rígido fué la fuente de reclamos contra la Corona que culminaron en la unión de fuerzas entre los barones y las ciudades libres de Inglaterra para obtener grandes concesiones en la famosa Carta Magna (1215) firmada por Juan I. Fueron concesiones de individualidad legal y garantías de procedimientos judiciales para el pueblo del país.

Las Cortes de Ley (Courts of Law), como ya hemos dicho, fueron limitadas en su jurisdicción por formas procesales. Esto ha dado lugar a mu chas situaciones injustas; esto sucedía cuando la sentencía ordenaba reparar daños mediante el pago de una suma de dinero, pero que no lo eran con justicia, o cuando personas fueron detenidas injustamente, o se tomaron medidas preventivas por conducta injusta de terceros cortra la propiedad. Tampoco fueron contempladas dichas resoluciones por las Cortes de Ley.

Por ejemplo: si una persona firmaba un cortrato para adquirir una propiedad y el vendedor se negaba a cumplirlo, el único camino que tenía el comprador era la acción por ruptura de contrato (special assumpsit), una solución dudosa en cuanto a su finalidad y que dió lugar a abusos de parte de especuladores.

En el campo de las investigaciones criminales, un inescrupuloso she- 
riff por razón de venganza personal podía encarcelar a un hombre inocente, Y éste no tenía más que esperar la llegada de las cortes de circuito que se desplazaban lentamente. Mientras tanto la libertad y la vida del inocente estaban completamente suspendidas.

Otro caso, el propietario de una finca invadida frecuentemente por su vecino, quien lo perjudicaba de esta manera, no tenía más derecho que el de demandarlo por daños cada vez que se producía la violación. Pero esta solución no presentaba garantía preventiva, ni sancionaba esa reincidencia, y, más bien, ponía al dueño de la finca en la situación desagradable de tener que presentarse continuamente ante los tribunales.

Para resolver estos problemas y otros provocados también por la rigidez de las Cortes de Ley, el inglés de los siglos 14 y 15 no tenía instituciones jurídicas a las cuales podía pedir justicia; entonces, el ciudadano. agraviadc se dirigía al propio Rey en: forma de "petición", la cual fué una de las concesiones obtenidas del Rey en la Carta Magna, suplicando que el mismo Rey dispensara justicia y equidad. Al hacerse más numerosas estas peticiones, por razón de la notoriedad lograda por la eficiencia de esta medicia, el Rey delegó su autoridad a sú propio ministro, el Canciller; y él, a su vez, por lo recargado de esta función, delegó su autoridad a subordirados, cuienes han venido a ser los jueces de las Cortes de Equidad (Courts of Equity) y de este origen histórico del poder del Canciller en estas materias resultó el nombre de Courts of Chancery, que se emplea aún hoy en determiriadas jurisdicciones.

Debe comprenderse que, al principio, esta organización judicial fué imperfecta y sujeta al abuso de autoridad y discreción; pero es un gran mérito para la conciencia judicial de los juristas ingleses de las Cortes de Equidad que fueron ellos mismos quienes limitaron su jurisdicción, y hoy día entre abogados y juristas de la "Common Law" es una definición bien conocida de los poderes de la Corte de Equidad la siguiente: La Equidad funciona solamente cuando no existe solución adecuada en la ley (Equity acts cnly wher there is no adequate remedy at Law). Naturalmente esto no es completamente cierto, porque no hay casos en los cuales la jurisdicción de la Equidad es concurrente con la jurisdicción de la Corte de Ley, pero como principio general este dicho explica bien la función de las Cortes de Equidad en: la "Common Law".

Conviene hacer notar que, en general, las Cortes de Equidad nunca trataron de convertirse en Cortes de Apelación y de anular las decisiones de las Cortes de Ley, aunque es posible que en el periodo formativo de su jurisdicción podrían ser descubiertos casos aislados en los cuales las Cortes de Equidad trataron de actuar de esta manera, pero su fin fué lograr una solución para casos en los que las Cortes de Ley, debido a lo limitado de su jurisdicción, no podían llegar a una solución adecuada y equitable.

Como lo hemos visto, en los tres casos mencionados anteriormente, la parte agraviada podía dirigirse a las Cortes de Ley, pero su solución ante ellas era en determinados casos inadecuada y ciertamente injusta. Las Cortes de Equidad establecieron entonces jurisdicción sobre los mismos hechos y los mismos sujetos jurídicos, pero con el objeto de atenuar la naturaleza restrictiva de los fallos de las Cortes de Ley y de esta manera administraban justicia al súbdito inglés.

Por consiguiente, las Cortes de Equidad constituyen una solución más justa en el primer caso, o sea el del concepto de la "ejecución especifica" 
(specific performance); dicho concepto, cuando el objeto de un contrato fuera singular de manera que la reparación de daños en dinero por la ruptura del contrato no podían decretarse con justicia, ya que los valores no eræn iguales g que el único fallo justo habria sido el cumplimiento del contrato como convenido entre las partes, el decreto obligaba al vendedor de la finca a transferir el título de la misma al comprador; así se cumplía la justicia.

En el segundo caso, las Cortes de Equidad proveyeron a la persona Injustamente detenida con el Writ of Habeas Corpus, el cual daba al detenido el derecho a ser juzgado inmediatamente ante el Juez de Equidad, exigiendo al Estado la justificación de la detención de esta persona. Si no había bese justa para la detención, la Corte de Equidad decretaba la liberación del detenido.

El tercer caso fué resuelto por la aplicación de la medida preventiva llamada injunction. Este decreto es una orden dada por la corte, dirigida a una persona, varias personas, o a un ente jurídico y que exige al sujeto hacer o no hacer un acto $u$ actos que son determinados por el juez como injustos o dañosos. Er: consecuencia, el vecino recalcitrante, que molesta o hace daños a la finca contigua por tránsito indebido y frecuente es notificado para gue cesen sus actos molestos o dañosos, bajo pena de multa o detención. Tal es el fallo judicial sobre el cual existen muchas controversias er relaciones entre obreros y patrones en los Etados Unidos. Una de las armas más poderosas de los sindicatos obreros es la "guardia huelguista" (picket line). Esta guardia se usa para prohibir al menos moralmente y muchas veces físicamente la entrada de otros obreros no huelguistas así como de clientes del centro en huelga, y tiene por consecuencia, paralizar las operaciones del patrono causante de la huelga .Para evitar esta coerción por los sindicatos obreros, los dueños de negocios objetos de esa medida han vuelto al uso del injunctión, decretado por la Corte de.Equidad, en el cual la corte ordenaba al sindicato, sus dirigentes y sus miembros que desistan y disuelvan la guardia bajo pena de multa y detención. En consecuencia, los sindicatos de obreros, una fuerza potente en la política de los Estados Unidos, anunciaron públicamente por medio de los principios de su organización, llamados planks, adoptados en las reuniones anuales, que ellos, los sindicatos deseaban la promulgación de leyes por las legislaturas de los diversos Estados y también por el gobierno nacional que prohibiesen el uso de la "injunction" por las Cortes de Equidad contra las guardias durante una huelga. Efectivamente este deseo de los sindicatos de obreros fué cumplido por el "Norris La Guardia Act" de 1933 y el "Wagner Labor Relations Act" de 1935.

Por razón de la naturaleza de las acciones en las Cortes de Equidad, que casi siempre se refieren a situaciones donde no hay cuestiones de hecho, sino solución de problemas de derecho, este sistema de jurisprudencia se desenvolvió sin el uso del jurado. El jurado en general es la espina dorsal del sistema de la Common Law, usado extensivamente tanto en casos civiles como en casos penales; pero en todos los casos el jurado ro determina más que los hechos y la aplicación de los derechos queda sin excepción bajo la jurisdicción del juez. En consecuencia, las Cortes de Equidad, siendo esencialmente llamadas para determinar cuestiones de derecho resuelven el caso sin jurado.

Ya que las Cortes de Equidad fueron cortes de primera instancia sus fallos estuvieron sujetos a revisión por apelación. Estas apelaciones fueron d- 
rigidas por las cortes superiores y el tribunal más alto de linglaterra, la Cámara Alta (House of Lords): Resultaba, pues, que estas cortes de apelación se ocupaban tanto de los litigios en las Cortes de Equidad, como de los casos provenientes de las Cortes de Ley. Jamás se consideraba a las Cortes de Equidad capaces de modificar fallos de las Cortes de Ley, representándose c.rmo cortes de apeláción de las Cortes de Ley. Las Cortes de Equidad. fueron $y$ son hoy día tribunales de primera instancia en un nivel igual al de las Cortes de Ley.

Actualmente las Cortes de Equidad han sido abolidas en algunas jurisdicciores, por ejemplo, en el Estado de Nueva York; en otros, el mismo juez es un día aceptado como juez de Equidad, y otro día como juez de Ley, ej. Pennsylvania; y en otras jurisdicciones quedan en funciones con un juzgado y administración separados, esto es er. el Estado de Nueva Jersey. Pero también en las jurisdicciones que ostensiblemente han abolido la identidad de las Cortes de Equidad, el espectro ya vive porque las acciones y prccedimientos necesarios para cumplir los fallos son indispensables y para conocer éstos es imperativo el estudio y el conocimiento de las fuentes, el desenvolvimiento y la jurtsdicción de las Cortes de Equidad. De manera que, hoy día, en las decisiones de la Corte Suprema del estado de Núueva York los jueces dar opiniones que citan principios de Equidad y se basan sobre ellos para fundamentar sus fallos.

Las Cortes de Equidad, por razón de los usos liberales del poder conferido a ellas for los Cancilleres y los Reyes cortribuirán a rompex la rigidez de las Cortes de Ley; en consecuencia el corto número de acciones en las Cortes de Ley, por la presencia de las Cortes de Equidad y el peligro de perder completamente su jurisdicción, fueron extendidos de manera que hoy las Cortes de Ley extienden su jurisdicción sobre muchos más casos que los que eran de su competencia en el siglo 15. Sin embargo, las Cortes de Equidad no han perdido todos sus poderes originarios y hoy día existe un balance de poderes respectivos; el período de rivalidad ertre Equidad y Ley ha desaparecido definitivamente hace más de cien años.

Por fin resulta que la mejor definición de la jurisdicción de las Cortes de Equidad es la que ha daclo de ellas uno de los primeros Cancilleres en. Equidad: "La Equidad obra solamente cuando no existe solución adecuada en la Ley (Equity acts orly when there is no adequate remedy at Law). 